\title{
Respiratory and symptomatic impact of ascites relief by paracentesis in patients with hepatic cirrhosis
}

\author{
Verônica Lourenço WITTMER ${ }^{1}$, Rozy Tozetti LIMA ${ }^{2}$, Michele Coutinho MAIA ${ }^{2}$, \\ Halina DUARTE ${ }^{1}$ and Flávia Marini PAR0 ${ }^{1}$
}

Received: 8 November 2019

Accepted: 6 January 2020

\begin{abstract}
Background - Liver cirrhosis is a highly prevalent disease that, at an advanced stage, usually causes ascites and associated respiratory changes. However, there are few studies evaluating and quantifying the impact of ascites and its relief through paracentesis on lung function and symptoms such as fatigue and dyspnea in cirrhotic patients. Objective - To assess and quantify the impact of acute reduction of ascitic volume on respiratory parameters, fatigue and dyspnea symptoms in patients with hepatic cirrhosis, as well as to investigate possible correlations between these parameters. Methods - Thirty patients with hepatic cirrhosis and ascites who underwent the following pre and post paracentesis evaluations: vital signs, respiratory pattern, thoracoabdominal mobility (cirtometry), pulmonary function (ventilometry), degree of dyspnea (numerical scale) and fatigue level (visual analog scale). Results - There was a higher prevalence of patients classified as CHILD B and the mean MELD score was 14.73 \pm 5.75 . The comparison of pre and post paracentesis parameters evidenced after paracentesis: increase of predominantly abdominal breathing pattern, improvement of ventilatory variables, increase of the differences obtained in axillary and abdominal cirtometry, reduction of dyspnea and fatigue level, blood pressure reduction and increased peripheral oxygen saturation. Positive correlations found: xiphoid with axillary cirtometry, degree of dyspnea with fatigue level, tidal volume with minute volume, Child "C" with higher MELD score, volume drained in paracentesis with higher MELD score and with Child "C". We also observed a negative correlation between tidal volume and respiratory rate. Conclusion - Since ascites drainage in patients with liver cirrhosis improves pulmonary volumes and thoracic expansion as well as reduces symptoms such as fatigue and dyspnea, we can conclude that ascites have a negative respiratory and symptomatological impact in these patients.
\end{abstract}

HEADINGS - Liver cirrhosis. Ascites. Respiratory system. Paracentesis.

\section{INTRODUCTION}

Liver cirrhosis is a chronic liver disease with high prevalence and impact on Brazilian public health ${ }^{(1,2)}$, accounting for over 29,000 deaths in $2010^{(1)}$. To classify the severity of liver disease and prioritize waiting lists for liver transplantation in Brazil, the Model for EndStage Liver Disease (MELD) score and the Child-Turcotte-Pugh score (CHILD) are widely used ${ }^{(3)}$. Once installed, liver failure triggers several secondary complications ${ }^{(4)}$, which may cause, among other consequences, the elevation of intra-abdominal pressure that causes diaphragmatic elevation, which results in increased intrathoracic pressure and compression of the lungs, impairing overall respiratory mechanics ${ }^{(5,6)}$. As an aggravation, patients with cirrhosis often develop malnutrition and sarcopenia, which possibly also affect respiratory mechanics ${ }^{(7)}$, triggering symptoms such as fatigue and dyspnea $^{(6,8)}$, complaints that are directly related to the functional condition and may cause limitations and restrictions to the patient $\mathrm{t}^{(9)}$.

However, despite evidence of respiratory changes in patients with ascites associated with liver cirrhosis, there are few studies evaluating and quantifying the impact of ascites and its relief through paracentesis on lung function and symptoms such as fatigue and dyspnea. In addition, we found no studies that investigated the correlation between respiratory, symptomatic and classificatory parameters (MELD and CHILD) of these patients.

Thus, the purpose of this study was to evaluate and quantify the impact of acute reduction in ascites volume on fatigue and dyspnea symptoms and respiratory parameters in patients with liver cirrhosis, as well as to investigate possible correlations between the parameters evaluated.

\section{METHODS}

Cross-sectional study with a convenience sample composed of patients who were admitted between January and December of 2018 at the gastroenterology sector of Hospital Universitário Cassiano Antônio de Moraes (HUCAM), in the city of Vitória-ES/Brazil, to perform paracentesis for relief of symptoms. The study included patients with a clinical diagnosis of liver cirrhosis who had indication of paracentesis for relief of ascites. Exclusion criteria were: hemodynamically unstable patients (sistolic blood pressure $<80$ $\mathrm{mmHg}$ ) and inability to understand and perform the procedures for evaluation and diagnosis of pulmonary diseases.

Declared conflict of interest of all authors: none

Disclosure of funding: no funding received

${ }^{1}$ Universidade Federal do Espírito Santo, Departamento de Educação Integrada em Saúde, Vitória, ES, Brasil. ${ }^{2}$ Universidade Federal do Espírito Santo, Empresa Brasileira de Serviços Hospitalares (EBSERH), Serviço de Fisioterapia, Vitória, ES, Brasil.

Corresponding author: Veronica Lourenço Wittmer, PhD. E-mail: ve_lourenco@yahoo.com.br 
All participants provided written consent after they were informed about the purpose and methods of the study. They were also informed that they could leave the study at any time without any loss of benefit. This study was approved by the Research Ethics Committee of Universidade Federal do Espirito Santo (approval number: 1.698.969). It was conducted in accordance with the Declaration of Helsinki and conducted in all its stages in accordance with Resolution 466/12 of National Health Council (Brazil), which regulates ethical aspects of research involving human subjects in Brazil.

After selection, the patients were evaluated to characterize the sample, and the following information was collected: age, gender, etiology of liver cirrhosis (when known), CHILD score and MELD index of all patients (evaluated by the medical team).

Vital signs (blood pressure, heart rate, respiratory rate and peripheral oxygen saturation) were then measured, and the type of breathing pattern was assessed by a dynamic inspection (whether predominantly abdominal, thoracic or thoracoabdominal). For recognition, we observed the movement of the chest and abdomen during breathing, locating in which regions the movements were most visible ${ }^{(10)}$. Subsequently, cirtometry was performed to assess thoracoabdominal mobility, with reference to the axillary, xiphoid and umbilical scars. The technique of positioning the tape measure around the thorax and abdomen was used, verifying the difference between the maximum inspiration and expiration measurement in the three reference points ${ }^{(10)}$. In this study, the values recommended by Carvalho (1994) $)^{(11)}$ were adopted as normality parameters, i.e., we considered that the cirtometry was reduced in patients who presented a difference between maximal inspiration and expiration below $4 \mathrm{~cm}$.

Dyspnea was assessed using the numerical scale in order to grade the intensity of the patient's respiratory distress at the time of assessment. The scale consists of a number from 0 to 10 , where 0 represents the absence of dyspnea and 10 the worst sensation of dyspnea ever felt or imagined by the patient ${ }^{(12)}$.

To assess fatigue, a visual analogue scale was applied, consisting of a $10 \mathrm{~cm}$ straight line, in which the patient marked with a vertical line representing the intensity of the fatigue he was feeling at the moment, with one extremity indicating absence of fatigue and the other one the worst fatigue imaginable ${ }^{(13)}$.

The evaluation of ventilometry was performed using the "Ventilômetro Análogo de Wright Mark 8" device attached to a mouthpiece. In basal respiration, minute volume and respiratory rate were simultaneously obtained, and tidal volume was determined by dividing minute volume by respiratory rate. Vital capacity was obtained by asking the patient to perform a maximal inspiration followed by a slow maximal exhalation. The tests were repeated three times and the highest values selected.

All measurements were performed with the patient in sedestation approximately 30 minutes before and 30 minutes after the patient underwent paracentesis.

For statistical analysis, the Statistical Package for Social Sciences (SPSS) software was used. The Shapiro-Wilk test was used to determine the normality of data distribution. In case of normal distribution, the Student's $t$-test was used. For variables where there was a breach of normality hypothesis, the Wilcoxon and McNemar tests were used. Changes in all variables were evaluated before and after paracentesis. To analyze the correlations between the evaluated parameters, the Spearman and Mann-Whitney correlation tests were used. To assess the strength of correlations, the following criterion was considered: if $0<\mathrm{r}<0.3$ : weak; if $0.3 \leq \mathrm{r}<0.6$ : moderate; if $0.6 \leq \mathrm{r}<0.9$ : strong; if $0.9 \leq \mathrm{r}<1$ : too strong $\mathrm{g}^{(14)}$. The values obtained were expressed as mean and standard deviation. $P$ values $<0.05$ were considered statistically significant.

\section{RESULTS}

Of the 35 patients initially selected, three were excluded due to inability to perform the proposed evaluations and 2 due to the diagnosis of associated respiratory diseases. Thus, the final sample consisted of 30 patients, 21 male and nine female, with ages ranging from 23 to 82 years $($ mean $=63.10 \pm 12.90)$.

Regarding the assessment of severity by the CHILD scale and the MELD score, our group consisted mostly of patients with CHILD score B (76.6\%) and the MELD scale presented an average score of $17.43 \pm 5.75$. The alcoholic etiology was the most prevalent $(43.3 \%)$, and most patients had one or more associated comorbidities. The volume drained in paracentesis ranged from 3 to 14 liters (mean $=6.59 \pm 2.86$ ). Regarding the breathing pattern, before paracentesis most patients had a predominance of thoracic $(43.3 \%)$ and thoracoabdominal $(43.3 \%)$ patterns, and after an increase $(P=0.022)$ of abdominal predominance $(43.3 \%)$. These data can be better seen in TABLE 1 .

TABLE 1. Demographic data and respiratory pattern of the studied patients.

\begin{tabular}{|c|c|c|}
\hline Variables & $\mathrm{n}$ & $\%$ \\
\hline \multicolumn{3}{|l|}{ Sex } \\
\hline Man & 21 & 70.0 \\
\hline Woman & 9 & 30.0 \\
\hline \multicolumn{3}{|l|}{ CHILD score } \\
\hline Child A & 1 & 3.3 \\
\hline Child B & 23 & 76.6 \\
\hline Child C & 6 & 20 \\
\hline \multicolumn{3}{|l|}{ Etiology of liver cirrhosis } \\
\hline Alcoholic & 13 & 43.3 \\
\hline Non-alcoholic steatohepatitis & 11 & 36.7 \\
\hline Hepatocellular carcinoma & 2 & 6.7 \\
\hline Schistosomiasis & 2 & 6.7 \\
\hline Hepatitis C & 2 & 6.7 \\
\hline Hepatitis B & 1 & 3.3 \\
\hline \multicolumn{3}{|l|}{ Comorbidities } \\
\hline Diabetes mellitus & 7 & 23.3 \\
\hline Systemic arterial hypertension & 6 & 20.0 \\
\hline Umbilical hernia & 3 & 10.0 \\
\hline Others & 10 & 33.3 \\
\hline \multicolumn{3}{|l|}{ Breathing pattern (initial) } \\
\hline Abdominal & 4 & 13.3 \\
\hline Thoracic & 13 & 43.3 \\
\hline Thoracoabdominal & 13 & 43.3 \\
\hline \multicolumn{3}{|l|}{ Breathing pattern (final) } \\
\hline Abdominal & $13 *$ & 43.3 \\
\hline Thoracic & 10 & 33.3 \\
\hline Thoracoabdominal & 7 & 23.3 \\
\hline
\end{tabular}


When comparing the ventilometric values obtained after paracentesis with the pre-paracentesis values, we observed the improvement of all analyzed parameters, as well as the reduction of dyspnea and fatigue. Regarding vital signs, after paracentesis, patients had reduced systolic and diastolic blood pressure, increased peripheral oxygen saturation and maintained heart rate values compared with values obtained before the procedure.

For the assessment of thoracoabdominal mobility (cirtometry), two analyzes were performed, that is, we verified if the initial values were lower than expected for the patients and also verified if they presented alterations after paracentesis. Abdominal mobility was the lowest among the three reference points evaluated $(1.86 \pm 1.09$ $\mathrm{cm})$, followed by axillary $(2.64 \pm 1.08 \mathrm{~cm})$ and xiphoid $(2.79 \pm 2.00$ $\mathrm{cm})$. When comparing the values obtained in the cirtometry with the normal parameters, we observed a reduction in the three reference points: axillary $(P=0.021)$, xiphoid $(P=0.041)$ and abdominal $(P=0.002)$. Comparing the means obtained in the three points to each other, the abdominal mobility was significantly lower in relation to the axillary $(P=0.021)$. When we evaluated the impact of paracentesis on the difference between maximal inspiration and expiration of patients at the three reference points, we found increased thoracoabdominal mobility after paracentesis at the axillary and abdominal points, while the xiphoid cirtometry remained unchanged. The comparison data of the parameters evaluated at the pre and post paracentesis moments can be seen in TABLE 2.

TABLE 2. Clinical parameters before and after relief of ascites through paracentesis

\begin{tabular}{lccc}
\hline Variables & $\begin{array}{c}\text { Before } \\
\text { paracentesis } \\
(\text { Mean } \pm \text { SD) }\end{array}$ & $\begin{array}{c}\text { After } \\
\text { paracentesis } \\
\text { (Mean } \pm \text { SD) }\end{array}$ & $P$-value* \\
\hline Ventilometry & $1.72 \pm 0.98$ & $1.99 \pm 1.10$ & $0.000^{*}$ \\
$\quad$ Vital capacity (L) & $8.46 \pm 4.03$ & $9.62 \pm 5.96$ & $0.001^{*}$ \\
Minute volume (L) & $15.50 \pm 3.79$ & $13.97 \pm 3.49$ & $0.000^{*}$ \\
Respiratory rate (bpm) & $0.56 \pm 0.25$ & $0.69 \pm 0.32$ & $0.000^{*}$ \\
Tidal volume (L) & $5.23 \pm 2.73$ & $2.13 \pm 1.78$ & $0.000^{*}$ \\
Dyspnea scale & $5.78 \pm 2.19$ & $3.43 \pm 1.99$ & $0.000^{*}$ \\
Fatigue scale (cm) & & & \\
Vital signs & $120.07 \pm 17.60$ & $113.00 \pm 14.89$ & $0.001^{*}$ \\
SBP (mmHg) & $73.87 \pm 11.54$ & $70.20 \pm 10.31$ & $0.004^{*}$ \\
DBP (mmHg) & $76.83 \pm 14.68$ & $75.03 \pm 10.91$ & 0.205 \\
HR (b/m) & $96.73 \pm 2.20$ & $97.87 \pm 1.53$ & $0.000^{*}$ \\
SpO & & & \\
Cirtometry (Change) & $1.58 \pm 0.74$ & $2.43 \pm 1.91$ & $0.001^{*}$ \\
Axillary (cm) & $1.73 \pm 0.98$ & $1.97 \pm 1.03$ & 0.142 \\
Xiphoid (cm) & $1.42 \pm 0.53$ & $2.68 \pm 1.84$ & $0.000^{*}$ \\
Umbilical (cm) &
\end{tabular}

*Statistically significant difference $(P<0.05)$ between the evaluation of variables before and after paracentesis (Wilcoxon test). SBP: systolic blood pressure; DBP: diastolic blood pressure, $\mathrm{HR}$ : heart rate, $\mathrm{SpO}_{2}$ : peripheral oxygen saturation.

In the present study, we also investigated which parameters were correlated with each other and with the greater or lower variation obtained between the pre and post paracentesis moments. Regarding the ventilometric parameters, we observed that the tidal volume variation showed a moderate positive correlation with the minute volume variation $(P=0.022)$, i.e., as the tidal volume increased after paracentesis, the same occurred with minute volume. We also observed a moderate negative correlation between tidal volume and respiratory rate $(P=0.001)$, i.e., the greater the tidal volume gain after paracentesis, the lower the respiratory rate.

In the investigation of cirtometry in the three evaluated points we found a strong positive correlation $(P=0.002)$ between xiphoid and abdominal cirtometry (demonstrating that as xiphoid expandability increased, so did the abdominal expansion).

The dyspnea and fatigue scales showed a moderate positive correlation $(P=0.026)$ in the pre-paracentesis evaluation and a strong positive correlation in the post-paracentesis evaluation $(P=0.001)$, demonstrating that as dyspnea increased, so did fatigue. The fatigue scale was also positively associated with the CHILD score $(P=0.001)$, since individuals with category " $\mathrm{C}$ " in CHILD had higher averages on the scale than individuals in category "B". However, we did not find a significant association of these scales with ventilometry variables and peripheral oxygen saturation.

When we investigated whether there was a correlation between the magnitude of the volume drained in paracentesis and the other parameters, we found only a positive correlation between the severity of the disease and this volume, that is, patients with higher means of MELD and greater severity in the CHILD score drained a larger volume of liquid $(P=0.000)$.

\section{DISCUSSION}

In the present study we observed a higher prevalence of male patients, with the alcohol etiology being more frequently observed, which is in agreement with another study conducted in Brazil ${ }^{(15)}$. Regarding the degree of liver dysfunction according to the CHILD classification, we observed a higher prevalence of CHILD B, followed by $\mathrm{C}$ and $\mathrm{A}$ respectively. When we correlate the score obtained on the MELD scale and the CHILD score with the volume drained in paracentesis, we find a positive correlation, which shows us that the more severe the patient, the higher the ascites presented by him, which corroborates with previous studies, which show that ascites is a common form of manifestation of liver cirrhosis descompensation that is associated with a worse prognosis ${ }^{(1-3)}$.

In the present study, we did not compare ventilometry values with those predicted for these patients, because the reference values are calculated based on the patients' weight and, since our patients had massive ascites, this would certainly increase body weight and could lead to a misinterpretation. However, since after paracentesis patients had increased all ventilometric parameters measured, we deduced that ascites really reduced ventilometry, although, we did not find other studies that evaluated through ventilometry the respiratory impact of ascites relief. In addition, previous studies with spirometry have observed reduction on lung volumes and on forced vital capacity in patients with cirrhosis ${ }^{(5,6)}$, which corroborates our hypothesis.

We know that reduced lung volumes can affect gas exchange and lead to inadequate oxygenation ${ }^{(5,6)}$. However, in our study, most patients had normal peripheral oxygen saturation values, which we believe to be due, at least in part, to a compensatory increase in pre-paracentesis respiratory rate, since after paracentesis we observed a significant reduction in respiratory rate and improvement in peripheral oxygen saturation.

Regarding the assessment of thoracoabdominal mobility performed by cirtometry, we observed a reduction in the three reference points in the pre-paracentesis evaluation when compared to predicted values, and an increase in the axillary and abdominal 
points after paracentesis. However, at the xiphoid point, we did not observe significant improvement after paracentesis. Although we have not found studies that investigated through cirtometry the changes in thoracic mobility of cirrhotic patients after paracentesis, we can infer from the studies of respiratory mechanics physiology the probable explanation for this result. When the diaphragm contracts during inspiration, its apposition zone in the lower ribs decreases, and the diaphragmatic dome presents caudal movement causing displacement out of the ventral wall of the abdomen. In addition, the diaphragm exerts two types of forces on the ribs of the lower chest, the insertion and the appositional, by transmitting abdominal pressure laterally to the lower ribs of the costal grating in the apposition zone, leading to an increase in anteroposterior and transverse diameters of lower ribcage ${ }^{(16)}$. When the abdomen receives mechanical support, insertion and appositional forces increase so that the muscle produces greater expansion of the lower ribcage ${ }^{(16,17)}$. During ascites, increased intra-abdominal pressure causes a significant reduction in caudal displacement of the diaphragmatic dome on inspiration, with consequent reduction in abdominal expansibility, which causes an increase in the apposition zone and of the laterally directed force against the lower ribs, partially compensating the reduction of the expandability that occurs due to the impossibility of adequate contraction of the cranially displaced diaphragm. The lower thorax region also undergoes the action of the intercostal muscles, which possibly participate in this compensation ${ }^{(18)}$. These factors may partially compensate the reduction of the thoracic expandability caused by ascites. This partial compensation may have reduced the difference between the pre and post paracentesis expandability values in the xiphoid region. Corroborating this hypothesis, the results also showed that, in both pre and post paracentesis measurements, the average xiphoid thoracic mobility was higher than the average of the other two regions (axillary and abdominal), although the three were reduced when compared reference parameters, reinforcing the hypothesis of partial compensation.

The increase in intra-abdominal pressure may also be the explanation for the changes in breathing pattern observed in the present study, since pre paracentesis most of the patients showed a predominantly thoracic and thoracoabdominal patterns and only a minority had a predominantly abdominal pattern. In addition, after paracentesis, we found an increase in the abdominal pattern in the patients, which suggests a reduction in the mechanical limitation of diaphragmatic activity exerted by ascites.

Thus, we deduced that the improvement in respiratory parameters observed after paracentesis is probably due to the improvement in respiratory mechanics induced by a reduction in intra-abdominal pressure which consequently improved diaphragmatic mechanics and pulmonary ventilation.

Corroborating our findings, other studies describe that ascites may cause respiratory repercussions ${ }^{(6,19-23)}$. The studies by Nagral et al. ${ }^{(19)}$ and Al-Zanaty et al. ${ }^{(22)}$ evaluated the pulmonary function by spirometry of patients liver cirrhosis with and without ascites, and observed that both groups had reductions in lung volume and capacity, and these reductions were greater in patients with ascites, suggesting two important outcomes, that is, firstly, that ascites worsens the lung function of cirrhotic patients, but, moreover, these results show that ascites is not the only cause of these patients' respiratory changes, since after paracentesis the pulmonary function improved but without complete restoration.
Since cirrhosis is also associated with malnutrition, sarcopenia, among other dysfunctions ${ }^{(7)}$, these factors may contribute to the worsening of pulmonary function and culminate in the onset of various signs and symptoms. Previous studies ${ }^{(8,9)}$ observed symptoms such as dyspnea and fatigue in patients with cirrhosis, which some authors ${ }^{(6,9)}$ believe that occurred as a consequence of the compressive effects of ascites on the respiratory system, malnutrition and low tissue oxygenation. These findings are in agreement with ours, since, through the applied scales, we observed that all pre-paracentesis patients presented dyspnea and fatigue to a greater or lesser grade, and after paracentesis we found a reduction in these symptoms, which we believe that has been due to a reduction in the compressive effects of ascites and an improvement in the effectiveness of the respiratory system. However, although perceptions of fatigue and dyspnea decreased after paracentesis, these symptoms did not disappear completely, reinforcing the hypothesis that these symptoms presented by patients with liver cirrhosis are multifactorial. Correlating the two scales, we observed a significant and positive association between them, showing that as dyspnea increases, so does fatigue, suggesting that both symptoms may be caused by the same factors.

The investigation of the correlation between the MELD and the CHILD scores with the other parameters showed a positive correlation of both with the volume drained in paracentesis, suggesting that the more severe the patient, the greater ascites. However, we did not observe any association between these indices and measures of cirtometry, dyspnea, fatigue, peripheral oxygen saturation and respiratory rate, reinforcing once again the hypothesis that these patients' respiratory alterations and symptoms are caused by multiple factors.

We conclude that patients in the most advanced classes of cirrhosis have higher ascites, which has a negative impact on lung volumes and chest expansion, aggravating symptoms such as fatigue and dyspnea. Our data suggest that respiratory changes and symptoms such as fatigue and dyspnea in these patients are caused by multiple factors, and not just by the respiratory limitation due to ascites. However, although ascites is probably not the only factor responsible for the observed respiratory changes, it certainly contributes to the worsening of lung function in patients, which we can conclude based on the remarkable improvement in fatigue, dyspnea and respiratory parameters after the paracentesis. We suggest further studies to better understand the respiratory and symptomatic repercussions of cirrhosis in association with ascites.

\section{Authors' contribution}

Wittmer VL: participated in the elaboration of the project, bibliographic search, data collection, data analysis and writing of the article. Lima RT, Maia MC: participated in the elaboration of the project and data collection. Duarte $\mathrm{H}$ : participated in the elaboration of the project, data analysis and writing of the article. Paro FM: participated in the elaboration of the project, bibliographic search, data collection, data analysis and writing of the article.

\section{Orcid}

Verônica Lourenço Wittmer: 0000-0002-3552-8169.

Rozy Tozetti Lima: 0000-0002-4736-8879.

Michele Coutinho Maia: 0000-0002-5586-715X.

Halina Duarte: 0000-0003-4029-6558.

Flávia Marini Paro: 0000-0003-1715-3778. 
Wittmer VL, Lima RT, Maia MC, Duarte H, Paro FM. Impacto respiratório e sintomatológico do alívio da ascite através da paracentese em pacientes com cirrose hepática. Arq Gastroenterol. 2020;57(1):64-8.

RESUMO - Contexto - A cirrose hepática é uma doença altamente prevalente que, em estágio avançado, geralmente causa ascite e alterações respiratórias associadas. No entanto, existem poucos estudos avaliando e quantificando o impacto da ascite e do seu alívio através da paracentese na função pulmonar e em sintomas como fadiga e dispneia em pacientes cirróticos. Objetivo - Avaliar e quantificar o impacto da redução aguda do volume ascítico nos parâmetros respiratórios, sintomas de fadiga e dispneia em pacientes com cirrose hepática, bem como investigar possíveis correlações entre esses parâmetros. Métodos - Trinta pacientes com cirrose hepática e ascite foram submetidos às seguintes avaliações pré e pós-paracentese: sinais vitais, padrão respiratório, mobilidade toracoabdominal (cirtometria), função pulmonar (ventilometria), grau de dispneia (escala numérica) e nível de fadiga (escala visual analógica). Resultados - Houve maior prevalência de pacientes classificados como CHILD B e o escore MELD médio foi de 14,73 $\pm 5,75$. A comparação dos parâmetros pré e pós paracentese evidenciou após a paracentese: aumento do padrão respiratório predominantemente abdominal, melhora das variáveis ventilatórias, aumento das diferenças obtidas na cirtometria axilar e abdominal, redução do nível de dispneia e fadiga, redução da pressão arterial e aumento da saturação periférica de oxigênio. Correlações positivas encontradas: cirtometria xifoide com axilar, grau de dispneia com nível de fadiga, volume corrente com volume minuto, CHILD "C" com maior escore MELD, volume drenado na paracentese com maior escore MELD e com CHILD "C". Também observamos uma correlação negativa entre volume corrente e a frequência respiratória. Conclusão - Uma vez que a drenagem da ascite em pacientes com cirrose hepática melhora os volumes pulmonares e a expansão torácica, além de reduzir sintomas como fadiga e dispneia, podemos concluir que a ascite tem um impacto respiratório e sintomatológico negativo nesses pacientes.

DESCRITORES - Cirrose hepática. Ascite. Sistema respiratório. Paracentese.

\section{REFERENCES}

1. Silveira LR, Iser BP, Bianchini F. Prognostic factors in patients hospitalized for liver cirrhosis in South of Brazil. GED Gastroenterol Endosc Dig. 2016;35:41-51.

2. Nader LA, de Mattos AA, Bastos GA. Burden of liver disease in Brazil. Liver International. 2014;34:844-9.

3. Durand F, Valla D. Assessment of the prognosis of cirrhosis: Child-Pugh versus MELD. J Hepatol. 2005;42(Suppl 1):S100-7.

4. D'Amico G, MorabitoA, D’AmicoM, PastaL, MaliziaG, ReboraP, et al. Clinical states of cirrhosis and competing risks. J Hepatol. 2018;68:563-76.

5. Yao EH, Kong B, Hsue G, Zhou A, Wang H. Pulmonar function changes in cirrhosis of the liver. Am J Gastroenterol. 1987;82:352-4.

6. Nitrini MA, Stirbulov R, Rolim EG. Influence of ascites in the pulmonary function of patients with portal hypertension. J Bras Pneumol. 2004;30:14-9.

7. Montano-Loza AJ. Clinical relevance of sarcopenia in patients with cirrhosis. Word J Gastroenterol. 2014;20:8061-71.

8. Norman LS. Pulmonary Complications of Cirrhosis. Gastroenterol Hepatol. 2015;11:126-8.

9. Rosa H, Júnior EL, Castro MA, Lamounier RS, Rocha RS. Estudo clínico da fadiga na cirrose alcoólica e não-alcoólica. GED Gastroenterol Endosc Dig. 2011;30:138-41.

10. Porto CC, Porto AL. Semiologia Médica. 7ed. Rio de Janeiro: Guanabara Koogan, 2014.

11. Carvalho, A.A. Semiologia em reabilitação. Atheneu. 1994.

12. Gift AG, Narsavage G. Validity of the numeric rating scale as a measure of dyspnea. Am J Crit Care. 1998;7:200-4.

13. Hewlett S, Dures E, Almeida C. Measures of Fatigue. Arthritis Care Res (Hoboken). 2011;639:263-86.
14. Callegari-Jacques, S.M. Bioestadística. Princípios e Aplicações. Porto Alegre: Artmed, 2003

15. Costa JK, Assis SL, Brilhante V, Guimarães AP. Perfil epidemiológico dos pacientes portadores de cirrose hepática atendidos no Ambulatório de Hepatologia do Centro de Especialidades Médicas do CESUPA (CEMEC), em Belém-PA. GED Gastroenterol Endosc Dig. 2016;35:1-8.

16. Troyer AD, Wilson TA. Action of the diaphragm on the rib cage. J Appl Physiol, 2016;121:391-400

17. De Troyer A, Wilson TA. Mechanism of the increased rib cage expansion produced by the diaphragm with abdominal support. J Appl Physiol. 2015;118:989-95.

18. Ward ME, Ward JW, Macklem PT. Analysis of human chest wall motion using a two-compartment rib cage model. J Appl Physiol. 1985;72:1338-47.

19. Nagral A, Kolhatkar VP, Bhatia SJ, Taskar VS, Abraham P. Pulmonary function tests in cirrhotic and non-cirrhotic portal hypertension. 1993;12:36-40.

20. Thenmozhi R, Jayaraman RM, Anandan H, Rao BV. Pulmonary Functions and Respiratory Efficiency in Patients with Cirrhosis and Portal Hypertension. International Journal of Scientific Study. 2016;4:114-7.

21. Abelmann WH, Frank NR, Gaensler EA, Cugell DW. Effects of abdominal distention by ascites on lung volumes and ventilation. AMA Arch Intern Med. 1954;93:528-40.

22. Al-zanaty TH, Hegazy MA, Aboulsoud SH, El-khabery HM, Mohamad SO. The prevalence of hypoxemia and abnormal ventilator functions in cirrhotic patients with and without ascites. Med J Cairo Univ.2010;78:59-65.

23. Stockton KA. Exercise training in patients with chronic liver disease. Physiother Theory Pract. 2001;17:29-38. 